\title{
CRESCIMENTO E PRODUTIVIDADE DO ALGODOEIRO HERBÁCEO SUBMETIDO À ADUBAÇÃO ORGÂNICA
}

Matheus Martins Ferreira' ${ }^{1}$, Francilene de Lima Tartaglia ${ }^{2}$, Fernando Sintra Fulaneti ${ }^{3}$, Cicera Carlos de Alencar ${ }^{3}$, Eloá Matos dos Santos ${ }^{3}$, Gibran da Silva Alves ${ }^{4}$

\begin{abstract}
RESUMO - A adubação orgânica é uma forma de reduzir a entrada de fertilizantes inorgânicos e baixar o custo de produção, manter o rendimento das culturas e a sustentabilidade do sistema produtivo. Objetivou avaliar o crescimento e a produtividade do algodoeiro herbáceo em função da adubação orgânica. O delineamento experimental adotado foi o inteiramente casualizado, distribuído em um fatorial para as variáveis de crescimento e unifatorial para as variáveis produtivas, com sete repetições. Os tratamentos foram compostos por três fontes de adubação: esterco bovino, palha de arroz carbonizada e solo sem adubação orgânica e períodos de avaliação. Cada unidade experimental foi composta por três vasos de polietileno preto de 18 litros cada, totalizando 63 vasos. Foi determinada a área foliar por planta, diâmetro do caule, altura de planta, número de ramos vegetativos, número de ramos reprodutivos, número de botões florais, número de maçãs por planta, massa seca da raiz e produtividade de pluma e caroço. De acordo com os resultados obtidos, a adubação orgânica melhorou o crescimento, desenvolvimento e a produtividade das plantas de algodão, sendo que o esterco bovino foi o que proporcionou os melhores resultados, incrementando em 101 e $108 \%$ a produtividade de fibra e caroço, respectivamente, em relação ao solo sem adubação orgânica.
\end{abstract}

Palavras chave: agroecologia, Gossypium hirsutum L., produção sustentável.

\section{GROWTH AND PRODUCTIVITY OF HERBACEOUS COTTON UNDER ORGANIC FERTILIZATION}

\begin{abstract}
The organic fertilization is a way to reduce the entry of inorganic fertilizers and lower the cost of production, maintain the yield of crops and the sustainability of the productive system. Objected evaluate the growth and productivity of the herbaceous cotton as a function of organic fertilization. The experimental design was the completely randomized, distributed in a factorial for the growth and unifatorial variables for the productive variables, with seven replications. The treatments were composed of three sources offertilization: cattle manure, carbonized rice straw and soil without organic fertilization and evaluation periods. Each experimental unit was composed of three black polyethylene pots of 18 liters each, totaling 63 vessels. The leaf area was determined by plant, stem diameter, plant height, number of vegetative branches, number of reproductive branches, number of floral buds, number of apples per plant, root dry mass and yield of feather and seed. According to the results, organic fertilization improved the growth, development and productivity of cotton plants, and cattle manure provided the best results, increasing by 101 and $108 \%$ the fiber and seed productivity, respectively, in relation to the soil without organic fertilization.
\end{abstract}

Keywords: agroecology, Gossypium hirsutum L., sustainable production.

\footnotetext{
${ }^{1}$ Mestrando em Agronomia, Universidade Federal de Santa Maria, Santa Maria, RS. E-mail para correspondência: math.ferreira10@yahoo.com.br

${ }^{2}$ Doutoranda em Fitotecnia, Universidade Federal Rural do Semi-Árido, Mossoró, RN.

${ }^{3}$ Acadêmicos de Agronomia, Universidade Federal do Pampa, Itaqui, RS.

${ }^{4}$ Docente do curso de Agronomia, Universidade Federal Rural do Pernambuco, Serra Talhada, PE.
} 


\section{INTRODUÇÃO}

O algodoeiro herbáceo (Gossypium hirsutum L.) é uma cultura que possui uma alta demanda nutricional, exigindo solos com boa fertilidade. No Brasil, a maioria dos solos cultivados com algodão é caracterizado por problemas de fertilidade, acidez elevada, toxidez por alumínio e alta fixação do fósforo (Lopes \& Guilherme, 2007). Em função disso é comum os produtores aplicarem grandes quantidades de fertilizantes químicos para elevar produtividade da cultura.

O uso de fertilizantes químicos, principalmente os nitrogenados, eleva a produtividade das culturas, no entanto, podem diminuir consideravelmente o $\mathrm{pH}$, alterar a comunidade microbiana do solo (Geisseler \& Scow, 2014) e causar poluição das águas subterrâneas e superficiais. Além disso, a aplicação excessiva e isoladamente de fertilizantes nitrogenados pode afetar a qualidade física do solo diminuindo a produtividade do sistema (Hati et al., 2008). Neste caso, a adubação orgânica é a alternativa mais benéfica, pois mantém a fertilidade do solo e a sustentabilidade da produção (Xin et al., 2016).

Na adubação orgânica, o uso contínuo de esterco em uma mesma área tende a aumentar a fertilidade do solo, principalmente os níveis de fósforo e nitrogênio (Pauletti et al., 2008). Além disso, o esterco melhora os atributos físicos do solo (Mellek et al., 2010; Yu et al., 2012) e aumenta o tamanho e a atividade da biomassa microbiana (Quadro et al., 2011), favorecendo supressão de agentes patogênicos, minimizando o risco econômico para os produtores, causado pelo baixo rendimento da cultura, devido a ocorrência de doenças de solo (Tao et al., 2015).

A adubação com fertilizantes minerais é uma prática de custo elevado na cultura do algodão, mas em contrapartida, o algodoeiro adubado com compostos orgânicos como o esterco bovino e a palha de arroz carbonizada pode ser uma forma de reduzir os custos com fertilizantes minerais e proporcionar melhor crescimento e produtividade da lavoura. Além disso, para os pequenos produtores é uma alternativa para a produção orgânica, que é isenta de insumos químicos.

O uso de esterco bovino no cultivo do algodoeiro pode promover aumentos na produtividade (Pereira et al., 2012). A palha de arroz carbonizada também pode ser uma alternativa para o cultivo da cultura, pois além de apresentar características físicas desejáveis, esse composto é encontrado em grande quantidade em regiões arrozeiras (Freitas et al., 2013). No entanto, há a necessidade de mais estudos para verificar os benefícios da adubação orgânica no crescimento e produtividade do algodão.

Objetivou-se com essa pesquisa avaliar o crescimento e a produtividade do algodoeiro herbáceo em função da adubação orgânica.

\section{MATERIAL E MÉTODOS}

O experimento foi conduzido em vaso e a céu aberto na Universidade Federal do Pampa (2909'21.68' S; $56^{\circ} 33^{\prime} 02.58^{\prime \prime} \mathrm{W} ; 74 \mathrm{~m}$ ), município de Itaqui -RS, no ano agrícola de 2013. O clima da região é do tipo Cfa, que segundo a classificação climática de Köppen é subtropical com verões quentes e sem estação seca definida (Wrege et al., 2011).

O delineamento experimental adotado foi inteiramente casualizado, distribuído em um fatorial para as variáveis de crescimento e unifatorial para as variáveis produtivas, com sete repetições. Para as variáveis de crescimento, os tratamentos foram compostos de três fontes de adubação: esterco bovino, palha de arroz carbonizada e solo sem adubação orgânica e períodos de avaliação, sendo que, para as variáveis, área foliar (AF), diâmetro do caule (DC) e altura de planta (AP) foram sete períodos de avaliação: 20,35, $50,65,80,95$ e 110 dias após a emergência (DAE) e para o número de ramos vegetativos planta ${ }^{-1}$ (NRV), número de ramos reprodutivos planta ${ }^{-1}$ (NRR), número de botões florais planta ${ }^{-1}$ (NBF) e número de maçãs planta $^{-1}(\mathrm{NM})$ foram cinco períodos: 50, 65, 80, $95 \mathrm{e}$ 110 DAE. Para as variáveis produtivas, os tratamentos foram compostos apenas pelas três fontes de adubação.

O esterco bovino e a palha de arroz carbonizada foram misturados com solo na proporção 1:1. Cada unidade experimental foi composta por 3 vasos de polietileno preto de 18 litros cada, totalizando 63 vasos. O solo utilizado como substrato foi classificado com Plintossolo háplico, os quais são formados sob condições de restrição à percolação de água, sujeitos ao efeito temporário de excesso de umidade e de maneira geral, imperfeitamente ou mal drenado (Embrapa, 2013). Foi realizada a análise química do esterco bovino, da palha de arroz carbonizada e do solo utilizado no experimento (Tabela 1). No solo misturado com esterco bovino e 
a palha de arroz carbonizada e no solo sem adubação orgânica foi realizada calagem, aplicando 3,65 T ha${ }^{1}$ de calcário dolomítico.

A semeadura foi realizada no dia 12 de outubro de 2013, sendo semeadas seis sementes por vaso, utilizando a cultivar BRS Araripe. 20 dias após a emergência (DAE) das plantas realizou-se o desbaste, deixando uma planta por vaso. A eliminação das plantas daninhas foi feita de forma manual, mantendo a cultura livre de competição até a colheita.

A AF foi estimada a partir da equação proposta por Fideles Filho et al. (2010), que constou em medir o comprimento da nervura principal de cada folha com uma régua milimetrada e em seguida aplicou-se a Equação (1), sendo que a soma da área de todas as folhas permitiu obter a área foliar da planta.

$$
\mathrm{Y}=0,7254 \mathrm{X}^{2,08922}
$$

Y é a área foliar por planta e X é o comprimento da nervura principal da folha de algodão.

O DC foi medido com o auxílio de um paquímetro digital, aproximadamente $4,0 \mathrm{~cm}$ acima da superfície do solo. AAP foi medida com uma trena milimetrada a partir do colo até a extremidade final da planta. O NRV, o NRR, o NBF e NM por planta foram determinados por contagem.

Os resultados produtivos foram estimados com os valores acumulados de três colheitas, pois nem todos os capulhos estavam prontos aos 120 DAE. A primeira colheita iniciou quando $50 \%$ dos capulhos estavam totalmente abertos, a segunda uma semana após a primeira e a terceira duas semanas após a primeira, colhendose os capulhos de todas as plantas.

Após a colheita foi determinado o número de capulhos por planta (NCP), massa total de capulhos (MTC), massa de um capulho (MUC), massa seca da raiz (MSR), produtividade de fibra (PF) e produtividade de caroço (PC).

O NCP foi determinado pela razão entre a quantidade de capulhos colhidos em cada unidade experimental (UE) e o número de plantas da UE. A MTC foi determinada pela razão entre a massa total de capulhos colhida na UE e número de plantas da UE. A MUC foi determinada pela razão entre a massa total de capulhos e número de capulhos colhidos em cada UE. Para determinação da massa seca da raiz, as plantas foram retiradas dos vasos e separadas a raiz da parte aérea, posteriormente as raízes foram lavadas em água corrente, acomodadas em sacos de papel e levadas a estufa de circulação forçada de ar a $70{ }^{\circ} \mathrm{C}$ por 72 horas, após esse período foram pesadas em balança analítica.

A PC foi determinada pela massa de caroço colhido em cada UE, após remoção da fibra. A PF de algodão foi determinada pela massa de fibra colhida em cada UE, após a remoção das sementes.

Os dados foram submetidos à análise de variância $(p<0,05)$ e quando verificado efeito significativo, aplicou-

Tabela 1 - Atributos químicos do esterco bovino, da palha de arroz carbonizada e do solo utilizado na adubação orgânica para cultivo do algodão BRS Araripe, Itaqui-RS

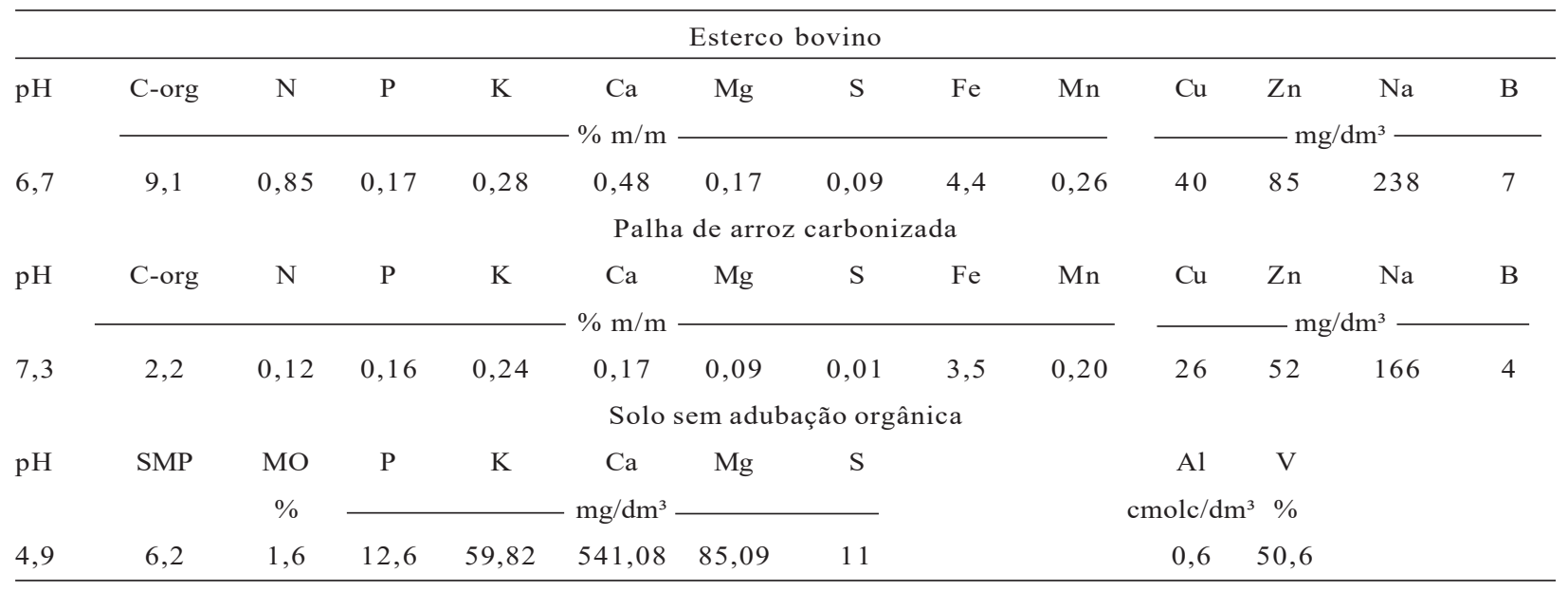


se a análise de regressão polinominal $(\mathrm{p}<0,05)$ para as variáveis quantitativas e o teste de $\operatorname{Scott-Knott~}(\mathrm{p}<0,05)$ para variáveis qualitativas utilizando o software Sisvar (Ferreira, 2011).

\section{RESULTADOS E DISCUSSÃO}

Houve interação significativa entre fontes de adubação (esterco bovino, palha de arroz carbonizada e solo sem adubação orgânica) e os períodos de avaliação (Dias após a emergência) sobre a área foliar, o diâmetro do caule e altura das plantas do algodoeiro (Tabela 2).

A adubação com esterco bovino proporcionou maior AF planta-1 (Tabela 4). AAF para o esterco bovino foi máxima aos $80 \mathrm{DAE}$, atingindo $2684,6 \mathrm{~cm}^{2} \mathrm{e}$ decrescendo após esse período (Figura $1 \mathrm{~A}$ ). O uso de solo sem adubo orgânico promoveu menor AF por planta em relação ao uso de esterco bovino e palha de arroz carbonizada (Tabela 4).

A AF é uma variável de grande importância para as plantas, pois está diretamente relacionada com produtividade (Pompelli et al., 2012). O uso do esterco bovino contribuiu para aumentos na AF do algodão, o que consequentemente ajudou para o incremento da produtividade, visto que, a correlação entre a área foliar e a produtividade de fibra e caroço foi de 0,85 e 0,81 , respectivamente. Os benefícios causados em função do uso do esterco bovino estão relacionados à melhoria das características físicas do solo, como porosidade, a capacidade de retenção de água, diminuição da densidade e melhoria da estabilidade dos agregados do solo (Rasool et al., 2007). Além disso, o esterco bovino disponibiliza grande quantidade de nutrientes para as plantas aumentando a $\mathrm{AF}$ e consequentemente a eficiência fotossintética da cultura (Costa et al., 2008).

As maiores médias para o diâmetro de caule e altura de plantas foram obtidas nas plantas que receberam esterco bovino como fonte de adubação (Tabela 4). $\mathrm{O}$ diâmetro do caule e a altura das plantas para o esterco bovino apresentaram valores máximos aos 86 e 90 DAE, com médias de $14,4 \mathrm{~mm}$ e 75,9 cm, respectivamente, sendo que, após esse período ocorreu tendência a decréscimo (Figura 1B e C). A palha de arroz carbonizada proporcionou médias intermediárias para o diâmetro do caule. Os menores valores de diâmetro de caule foram obtidos quando utilizou solo sem adubação orgânica, já para a altura das plantas, a palha de arroz carbonizada e o solo sem adubação orgânica apresentaram os menores valores (Tabela 4).

Resultados semelhantes para altura de plantas foram obtidos por Singh \& Ahlawat (2014) que, ao testarem fontes orgânicas e inorgânicas de nitrogênio para o algodoeiro, concluíram que o fornecimento de $25 \%$ do nitrogênio exigido pela cultura na forma de adubação orgânica proporcionou maior altura de plantas e maior índice de área foliar. Segundo os mesmos autores, esses resultados podem ser devido ao maior período de fornecimento de nutrientes pelo material orgânico, o que pode ter melhorado a atividade fotossintética da planta, contribuindo para aumentar os índices de crescimento das plantas.

O NRV e NRR planta ${ }^{-1}$ foram influenciados significativamente pelas fontes de adubação e pelos períodos de avaliação (DAE). Houve interação significativa entre os fatores para o NBF e NM planta ${ }^{-1}$ (Tabela 3).

Tabela 2 - Resumo da análise de variância para verificação dos fatores fontes de adubação orgânica e dias após a emergência sob as variáveis área foliar (AF), diâmetro de caule (DC) e altura de planta (AP) do algodoeiro BRS Araripe

\begin{tabular}{lcccc}
\hline & & & QM \\
\cline { 3 - 5 } Fontes de variação & GL & AF & DC & AP \\
\hline Fontes de adubo (FA) & 2 & $10624988,86 * *$ & $79,59 * *$ & $1208,65 * *$ \\
Dias após a emergência (DAE) & 6 & $13530130,77 * *$ & $273,72 * *$ & $10833,33 * *$ \\
FA x DAE & 12 & $643470,82 * *$ & $3,14 * *$ & $43,21 * *$ \\
Erro & 126 & 165474,55 & 0,75 & 19,77 \\
Total & 146 & - & - & - \\
CV $(\%)$ & - & 30,52 & 8,49 & 8,74 \\
\hline
\end{tabular}

$* *=$ significativo a $1 \%$ de probabilidade pelo teste $\mathrm{F}$. 

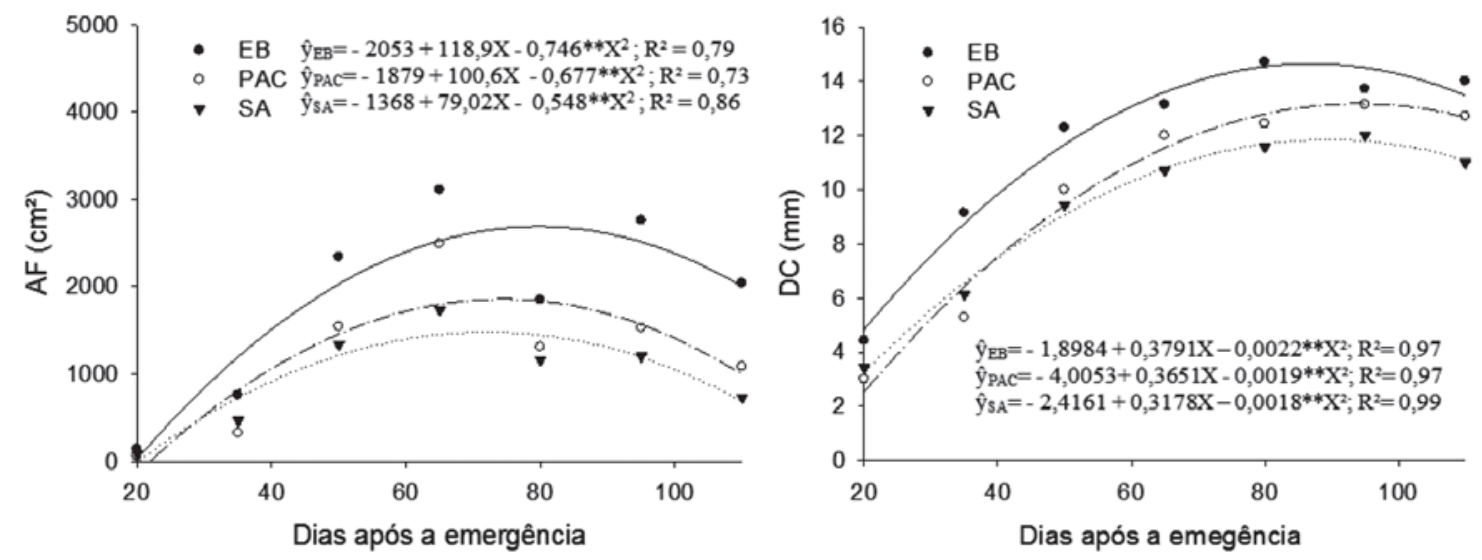

$\mathrm{C}$

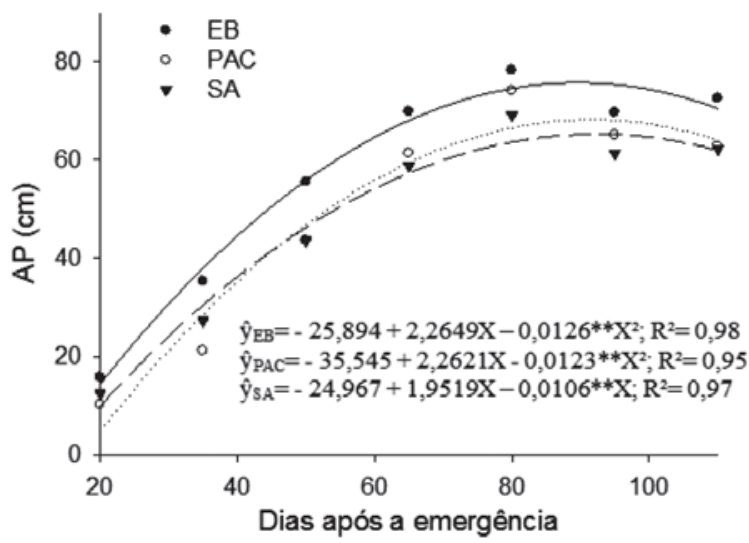

Figura 1 - Área foliar (A), diâmetro de caule (B) e altura de plantas (C) do algodoeiro BRS Araripe em função de dias após a emergência e diferentes fontes de adubação orgânica, esterco bovino (EB), palha de arroz carbonizada (PAC) e solo sem adubação orgânica (SA).

Tabela 3 - Resumo da análise de variância para verificação dos fatores fontes de adubação orgânica e dias após a emergência sob as variáveis número de ramos vegetativos planta ${ }^{-1}(\mathrm{NRV})$, número de ramos reprodutivos planta ${ }^{-1}(\mathrm{NRR})$, número de botões florais planta ${ }^{-1}(\mathrm{NBF})$ e número de maçãs planta ${ }^{-1}(\mathrm{NM})$ do algodoeiro BRS Araripe

\begin{tabular}{lccccc}
\hline & & \multicolumn{3}{c}{ QM } \\
\cline { 3 - 6 } Fontes de variação & GL & NRV & NRR & NBF & NM \\
\hline Fontes de adubo (FA) & 2 & $10,86^{* *}$ & $40,26^{* *}$ & $80,58 * *$ & $119,34 * *$ \\
DAE & 4 & $6,91^{* *}$ & $70,72^{* *}$ & $1435,69 * *$ & $702,01 * *$ \\
FA x DAE & 8 & $0,84^{\text {NS }}$ & $2,95^{\text {NS }}$ & $25,60 * *$ & $28,98 * *$ \\
Erro & 90 & 0,75 & 1,5 & 4,55 & - \\
Total & 104 & - & - & 27,51 & 31,47 \\
CV $(\%)$ & - & 25,07 & 16,78 & 27 & - \\
\hline
\end{tabular}

$* *,{ }^{N S}=$ significativo a $1 \%$ de probabilidade e não significativo, respectivamente, pelo teste $\mathrm{F}$. 
O maior NRV e NRR foram obtidos quando se utilizou como fonte de adubo o esterco bovino. A palha de arroz carbonizada apresentou valores intermediários, entretanto, quando se utilizou solo sem adubação orgânica, as plantas produziram significativamente menor NRV e NRR (Tabela 4). O número de ramos vegetativos aumentou linearmente em função dos dias de avaliação, já o NRR foi máximo aos 96 DAE, sendo de 11,5 ramos planta $^{-1}$ e diminuindo após esse período (Figura 2A).

O esterco bovino proporcionou maior NBF, enquanto o solo sem adubação orgânica proporcionou os menores valores (Tabela 4). O NBF máximo para o esterco bovino foi obtido aos 65 DAE, sendo de 16 botões planta ${ }^{-1}$. Para o NM, o esterco bovino foi igual à palha de arroz carbonizada, os quais obtiveram os melhores resultados (Tabela 4). O NM máximo para o esterco bovino e a palha de arroz carbonizada foi obtido aos 87 e $95 \mathrm{DAE}$, encontrando-se 14 e 12 maçãs planta ${ }^{-1}$, respectivamente. Após esses períodos ocorreu redução nos mesmos (Figura 2C e 2D)..

De acordo com Constable \& Bange (2015), para atingir altas produtividades no algodoeiro é necessário ter um maior número de ramos reprodutivos e de maçãs por $\mathrm{m}^{2}$. Nesse caso o esterco bovino se mostrou um excelente composto orgânico, pois aumentou o NRR e NM. Lacerda \& Silva (2007) comparando adubação orgânica, esterco de galinha e esterco bovino, em sistema de plantio direto e convencional em algodão, concluíram que o uso de esterco de galinha, nos dois sistemas de plantio, proporcionou maior número de maçãs por planta, maior massa de capulho por planta e maior número de massa de sementes por planta em relação ao uso de esterco bovino. Os mesmos autores concluíram ainda que esses resultados foram creditados aos maiores teores de N, P e K do esterco de galinha em relação ao esterco bovino. Neste trabalho, o esterco bovino foi melhor do que a palha de arroz carbonizada, o que também pode está relacionado ao maior teor de nutrientes, como pode ser observado na Tabela 1 .

As fontes de adubo influenciaram significativamente o NCP, MTC, MUC, MSR, PF e PC do algodão BRS Araripe (Tabela 5).

As variáveis de produção seguiram a tendência das variáveis de crescimento, sendo que o maior NCP e a maior MSR foram obtidos quando se utilizou o esterco bovino e a palha de arroz carbonizada. Significativamente os menores valores foram obtidos para as plantas cultivadas no solo sem adubação orgânica. O esterco bovino proporcionou a maior MTC, já a menor massa de capulhos foi obtida no solo sem adubo orgânico (Tabela 6).

Os capulhos mais pesados foram aferidos nas plantas adubadas com esterco bovino e no solo sem adubação orgânica. Já o uso de palha de arroz carbonizada proporcionou significativamente menor massa unitária de capulhos (Tabela 6). A maior MUC nos tratamentos com solo sem adubação orgânica pode ter sido em função do menor NCP e o menor número de ramos vegetativos, pois, uma menor quantidade de tecidos drenos resulta em menor competição pelos fotoassimilados que estão sendo exportados pelas fontes (Taiz \& Zeiger, 2009), assim proporcionando maior acúmulo pelos frutos e resultando em capulhos mais pesados.

As maiores produtividades, tanto de fibra quanto de caroço de algodão, foram significativamente aferidas nos tratamentos onde se utilizou esterco bovino. Os demais sistemas de cultivo, com palha de arroz carbonizada e solo sem adubação orgânica proporcionaram estatisticamente as menores produtividades (Tabela 6). As maiores produtividades obtidas com o uso de esterco bovino pode ser devido a maior disponibilidade

Tabela 4 - Área foliar (AF), diâmetro do caule (DC), altura de planta (AP), número de ramos vegetativos (NRV) e número de ramos reprodutivos (NRR), número de botões florais planta ${ }^{-1}(\mathrm{NBF})$ e número de maçãs planta $^{-1}$ (NM) do algodoeiro BRS Araripe em função de diferentes fontes de adubação orgânica: solo sem adubação orgânica (SA), esterco bovino (EB) e palha de arroz carbonizada (PAC)

\begin{tabular}{cccccccc}
\hline Fontes de adubo & AF $\left(\mathrm{cm}^{2}\right)$ & DC $(\mathrm{mm})$ & AP $(\mathrm{cm})$ & NRV & NRR & NBF & NM \\
\hline SA & $956,9 \mathrm{c}$ & $9,2 \mathrm{c}$ & $48,0 \mathrm{~b}$ & $2,9 \mathrm{c}$ & $6,1 \mathrm{c}$ & $8,1 \mathrm{~b}$ & $6,2 \mathrm{~b}$ \\
EB & $1853,7 \mathrm{a}$ & $11,5 \mathrm{a}$ & $56,3 \mathrm{a}$ & $4,0 \mathrm{a}$ & $8,3 \mathrm{a}$ & $11,8 \mathrm{a}$ & $10,6 \mathrm{a}$ \\
PAC & $1188,0 \mathrm{~b}$ & $9,9 \mathrm{~b}$ & $48,7 \mathrm{~b}$ & $3,4 \mathrm{~b}$ & $7,5 \mathrm{~b}$ & $9,0 \mathrm{~b}$ & $9,5 \mathrm{a}$ \\
\hline
\end{tabular}

Letras iguais na coluna não diferem estatisticamente entre si pelo teste de Scott-Knott a 5\% de erro. 
de nutrientes (Tabela 1), visto que, a adição de esterco aumenta a atividade das enzimas urease, fosfatase e desidrogenase, as quais possuem papel importante no ciclo do nitrogênio, mineralização do fósforo a na atividade oxidativa da microflora do solo, respectivamente (Liang et al., 2014). Além disso, o longo período que os materiais ficaram misturados pode ter proporcionado maior liberação de nutrientes para as plantas.
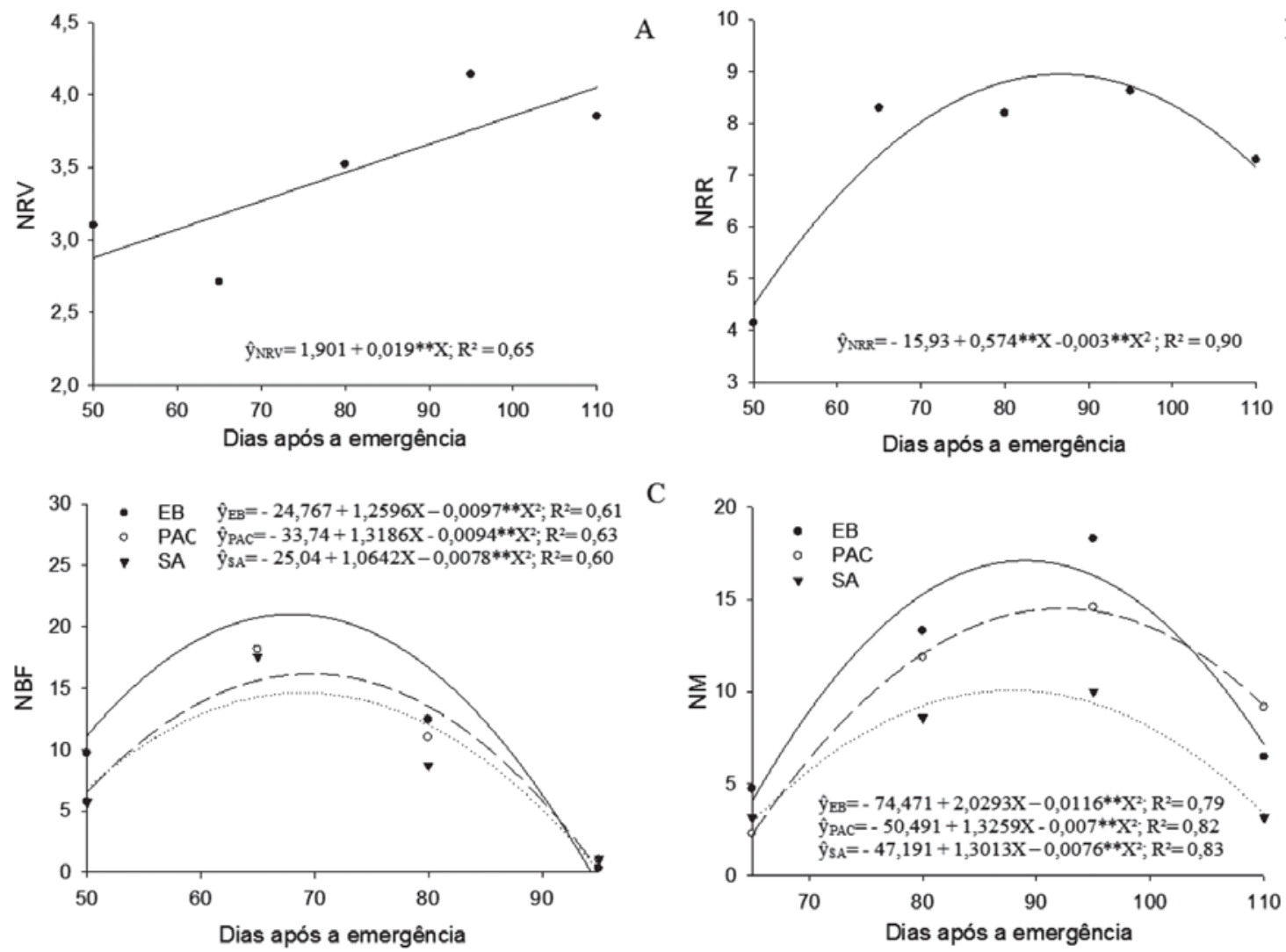

Figura 2 - Número de ramos vegetativos (A), número de ramos reprodutivos (B), número de botões florais (C) e número de maçãs (D) do algodoeiro BRS Araripe em função de dias após a emergência e diferentes fontes de adubação orgânica (C e D): esterco bovino (EB), palha de arroz carbonizada (PAC) e solo sem adubação orgânica (SA).

Tabela 5 - Resumo da análise de variância para as variáveis número de capulhos por planta (NCP), massa total de capulhos (MTC), massa de um capulho (MUC), massa seca da raiz (MSR), produtividade de fibra (PF) e produtividade de caroço (PC) do algodoeiro BRS Araripe cultivado com diferentes fontes de adubação orgânica

\begin{tabular}{lccccccc}
\hline \multirow{2}{*}{ Fontes de variação } & \multicolumn{7}{c}{ QM } \\
\cline { 2 - 8 } & GL & NCP & MTC & MUC & MSR & PF & PC \\
\hline Fontes de adubo & 2 & $96,64^{* *}$ & $5199,46^{* *}$ & $8,75^{* *}$ & $38,14^{* *}$ & $5503779,79 * *$ & $10446097,98^{* *}$ \\
Erro & 17 & 5,37 & 229,66 & 0,65 & 2,78 & 344668,68 & 779829,16 \\
Total & 19 & - & - & - & - & - & - \\
CV $(\%)$ & - & 20,84 & 20,71 & 11,99 & 22,72 & 22,24 & 25,33 \\
\hline
\end{tabular}

$* *=$ significativo a $1 \%$ de probabilidade pelo teste $\mathrm{F}$. 
Tabela 6 - Média das variáveis número de capulhos por planta (NCP), massa total de capulhos (MTC), massa de um capulho (MUC), massa seca da raiz (MSR), produtividade de fibra (PF) e produtividade de caroço (PC) do algodoeiro BRS Araripe cultivado com diferentes fontes de adubação orgânica, solo sem adubação orgânica (SA), esterco bovino (EB) e palha de arroz carbonizada (PAC)

\begin{tabular}{lcccccc}
\hline Fontes de adubo & NCP & MTC $(\mathrm{g})$ & MUC $(\mathrm{g})$ & MSR $(\mathrm{g})$ & PF $\left(\mathrm{kg} \mathrm{ha}^{-1}\right)$ & PC $\left(\mathrm{kg} \mathrm{ha}^{-1}\right)$ \\
\hline SA & $6,3 \mathrm{~b}$ & $44,63 \mathrm{c}$ & $6,8 \mathrm{a}$ & $4,36 \mathrm{~b}$ & $1.782,3 \mathrm{~b}$ & $2.298,5 \mathrm{~b}$ \\
EB & $13,2 \mathrm{a}$ & $101 \mathrm{a}$ & $7,7 \mathrm{a}$ & $8,65 \mathrm{a}$ & $3.586,7 \mathrm{a}$ & $4.787,5 \mathrm{a}$ \\
PAC & $13 \mathrm{a}$ & $69,7 \mathrm{~b}$ & $5,5 \mathrm{~b}$ & $8,6 \mathrm{a}$ & $2.426,1 \mathrm{~b}$ & $3.201,2 \mathrm{~b}$ \\
\hline
\end{tabular}

Médias seguidas por mesma letra na coluna não se diferenciam entre si pelo teste de Scott-Knott a $5 \%$ de probabilidade.

O uso de esterco bovino ocasionou aumento de $101 \%$ na produtividade de fibra em relação a não utilização de adubação orgânica e de $48 \%$ em relação ao uso da palha de arroz carbonizada. Já para à produtividade de caroço, o esterco bovino aumentou em 108\% a produtividade em relação a não utilização de adubação orgânica e $49 \%$ a mais que o uso de palha de arroz carbonizada.

Os melhores resultados produtivos com a utilização de esterco bovino também podem estar relacionados à maior presença de fungos micorrízicos arbusculares, que ajudam na absorção de nutrientes. De acordo com Dhawi et al. (2015), a colonização micorrízica aumenta significativamente alguns metabólitos secundários que estão correlacionados positivamente com o aumento da biomassa radicular, melhorando a absorção de nutrientes.

Em estudo realizado por Sousa et al. (2012), os autores concluíram que a utilização de esterco caprino proporcionou maior riqueza de espécies de fungos nos dois anos de cultivo e nas três culturas estudadas: milho, feijão e algodão. As raízes colonizadas por fungos micorrízicos podem ter um aumento de 3 a 5 vezes na taxa de absorção de P (Schachtman et al., 1998), portanto, um beneficio importante para o algodoeiro, visto que, o P é o primeiro macronutriente a responder sobre a produção da cultura (Staut \& Athayde, 1999).

A palha de arroz carbonizada (PAC) proporcionou valores intermediários, obtendo aumentos de $25,5 \%$, $16,6 \%, 5,5 \%$, para as variáveis $\mathrm{AF}, \mathrm{DC}, \mathrm{AP}, 17,2 \%, 22,3 \%$, $11,1 \%$ e $44,6 \%$, para as variáveis NRV, NRR, NBF e NM e 36,1\% e 39,3\%, para a PF e PC, respectivamente, em relação ao tratamento com apenas solo. Assim, a palha de arroz carbonizada torna-se uma alternativa para os locais onde não exista a disponibilidade de esterco bovino, podendo ser usada para melhorar as condições físicas e químicas do solo. Segundo Guerrini \& Trigueiro (2004), o uso de PAC aumenta a porosidade, diminui a densidade e aumenta os teores de $\mathrm{K}$ do substrato, possibilitando bons rendimentos quando não há a aplicação de adubo químico.

Com base nos resultados é possível inferir que a adubação orgânica aumenta o desempenho do algodoeiro herbáceo. Além disso, essa prática pode promover melhoria aos atributos do solo, pois melhora os agregados e aumenta a concentração de carbono orgânico do solo (Yu et al., 2012), estimula o desenvolvimento de micro-organismos, promove alterações na comunidade microbiana, aumentando a disponibilidade de nutrientes no solo (Liu et al., 2009). Esses benefícios ao solo contribuem para aumentos no rendimento e a qualidade da fibra do algodoeiro (Dias et al., 2016).

\section{CONCLUSÕES}

O uso de adubação orgânica potencializa o crescimento e aumenta a produtividade da cultura do algodão.

O esterco bovino proporciona maior crescimento e produtividade de caroço e fíbra de algodão, podendo transformar o algodão com base orgânica uma opção de renda para pequenos produtores.

\section{LITERATURA CITADA}

CONSTABLE, G.A.; BANGE, M.P. The yield potential of cotton (Gossypium hirsutum L.). Field Crops Research, v.182, n.1, p.98-106, 2015.

COSTA, L.C.B. et al. Tipos e doses de adubação orgânica no crescimento, no rendimento e na composição química do óleo essencial de elixir paregórico. Ciência Rural, v.38, n.8, p.2173-2180, 2008. 
DHAWI, F.; DATTA, R.; RAMAKRISHNA, W. Mycorrhiza and PGPB modulate maize biomass, nutrient uptake and metabolic pathways in maize grown in mining-impacted soil. Plant

Physiology and Biochemistry, v.97, n.1, p.390-399, 2015.

DIAS, A.S. et al. Crescimento e produção de algodoeiro de fibra colorida cultivado em solo salino-sódico e adubação orgânica. Irriga, v.1, n.1, p.260, 2018.

EMBRAPA - Empresa Brasileira de Pesquisa Agropecuária. Sistema brasileiro de classificação de solos. Rio de Janeiro: Embrapa solos, 2013. 353p. 3ed.

FERREIRA, D.F. Sisvar: a computer statistical analysis system. Ciência e Agrotecnologia, v.35, n.6, p.1039-1042, 2011.

FIDELES FILHO, J.; BELTRÃO, N.E.M.; PEREIRA, A.S. Desenvolvimento de uma régua para medidas de área foliar do algodoeiro. Revista Brasileira de Engenharia Agrícola e Ambiental, v.14, n.7, p.736-741, 2010.

FREITAS, G.A. et al. Production of lettuce seedlings under different substrates and proportions of rice hulls. Journal of Biotechnology and Biodiversity, v.3, n.1, p.260-268, 2013.GEISSELER, D.; SCOW, K.M. Long-term effects of mineral fertilizers on soil microorganisms - A review. Soil Biology and Biochemistry, v. 75, n.1, p.54-63, 2014.

GUERRINI, I.A.; TRIGUEIRO, R.M. Atributos físicos e químicos de substratos compostos por biossólidos e casca de arroz carbonizada.

Revista Brasileira de Ciência do Solo, v.28, n.6, p.1069-1076, 2004.

HATI, K.M. et al. Impact of long-term application of fertilizer, manure and lime under intensive cropping on physical properties and organic carbon content of an Alfisol. Geoderma, v.148, n.2, p.173-179, 2008.

LACERDA, N.B.; SILVA, J.R.C. Efeitos do manejo do solo e da adubação orgânica no rendimento do algodoeiro. Revista Brasileira de Engenharia Agrícola e Ambiental, v.11, n.2, p.167-172, 2007.
LIANG, Q. et al. Effects of 15 years of manure and mineral fertilizers on enzyme activities in particlesize fractions in a North China Plain soil.

European Journal of Soil Biology, v.60, n.1, p.112-119, 2014.

LIU, M. et al. Organic amendments with reduced chemical fertilizer promote soil microbial development and nutrient availability in a subtropical paddy field: The influence of quantity, type and application time of organic amendments. Applied Soil Ecology, v.42, n.2, p.166-175, 2009.

LOPES, A.S.; GUILHERME, L.R.G. Fertilidade do solo e produtividade agrícola. In: NOVAIS, R.F. et al. (ed.) Fertilidade do solo. Viçosa: Sociedade Brasileira de Ciência do solo, 2007. 1017p.

MELLEK, J.E. et al. Dairy liquid manure and notillage: Physical and hydraulic properties and carbon stocks in a Cambisol of Southern Brazil.

Soil and Tillage Research, v.110, n.1, p.6976, 2010.

PAULETTI, V. et al. Produtividade de culturas sob diferentes doses de esterco líquido de gado de leite e de adubo mineral. Scientia Agraria, v.9, n.2, p.199-205, 2008.

PEREIRA, J.R. et al. Doses de esterco bovino nas características agronômicas e de fibras do algodoeiro herbáceo BRS Rubi. Revista Agro@mbiente On-line, v.6, n.3, p.195-204, 2012.

POMPELLI, M.F. et al. Allometric models for nondestructive leaf area estimation of the Jatropha curcas L. Biomass and Bioenergy, v.36, n.1, p.77-85, 2012.

QUADRO, M.S. et al. Biomassa e atividade microbiana em solo acrescido de dejeto suíno.

Current Agricultural Science and Technology, v.17, n.1, p.85-93, 2011.

RASOOL, R.; KUKAL, S.S.; HIRA, G.S. Soil physical fertility and crop performance as affected by long term application of FYM and inorganic fertilizers in rice-wheat system. Soil and Tillage Research, v.96, n.1, p.64-72, 2007. 
SCHACHTMAN, D.P.; REID, R.J.; AYLING, S.M. Phosphorus uptake by plants: from soil to cell.

Plant physiology, v.116, n.2, p.447-453, 1998.

SINGH, R.J.; AHLAWAT, I.P.S. Growth Behaviour of Transgenic Cotton with Peanut Intercropping System Using Modified Fertilization Technique.

Proceedings of the National Academy of Sciences, India Section B:

Biological Sciences, v.84, n.1, p.19-30, 2014.

SOUSA, C.S. et al. Occurrence of arbuscular mycorrhizal fungi after organic fertilization in maize, cowpea and cotton intercropping systems.

Acta Scientiarum. Agronomy, v.34, n.2, p.149-156, 2012.

STAUT, L.A.; ATHAYDE, M.L.F. Efeitos do fósforo e potássio no rendimento e em outras características agronômicas do algodoeiro herbáceo. Pesquisa Agropecuária Brasileira, v.34, n.10, p.1839-1843, 1999.
TAIZ, L.; ZEIGER, E. Fisiologia vegetal. 4. Ed. Porto Alegre: Artmed, 2009. 848p.

XIN, X. et al. Effects of long-term (23 years) mineral fertilizer and compost application on physical properties of fluvo-aquic soil in the North China Plain. Soil and Tillage Research, v.156, n.1, p.166-172, 2016.

WREGE, M.S. et al. Atlas climático da Região Sul do Brasil: Estados do Paraná, Santa Catarina e Rio Grande do Sul. Embrapa Clima Temperado; Colombo: Embrapa Florestas, 2011.333p.

YU, H. et al. Long-term application of organic manure and mineral fertilizers on aggregation and aggregate-associated carbon in a sandy loam soil. Soil and Tillage Research, v.124, n.1, p.170-177, 2012.

Recebido para publicação em 28/12/2017 e aprovado em 27/6/2018. 